tipo gengival espesso optou-se pela realização de cirurgia de retalho de reposionamento lateral associado a um enxerto de tecido conjuntivo. Discussão e conclusões: Os enxertos gengivais pediculados baseiam-se na utilização do tecido gengival apical ou lateral à recessão e à sua movimentação de forma a recobrir a raiz. O recurso a esta técnica requer a presença de alguns requisitos: (1) quantidade suficiente de gengiva aderida ( $\geq 4 \mathrm{~mm}$ ) apical ou lateralmente à recessão, para movimentar; (2) idealmente um fenótipo gengival espesso ( $\geq 1 \mathrm{~mm}$ de espessura) por forma a dividir o retalho pediculado em espessura parcial e, (3) uma recessão gengival relativamente estreita ( $\leq 4 \mathrm{~mm}$ da largura radicular). Atendendo à falta de gengiva queratinizada optou-se por associar um enxerto de tecido conjuntivo, garantindo um aumento da espessura gengival maior do que a alcançada com o enxerto pediculado isoladamente. Adicionalmente permite a reposição dos parâmetros estéticos (morfologia e cor) perdidos. A correta seleção dos casos é fundamental para a obtenção dos resultados pretendidos, mas também para uma melhor gestão das expectativas do clínico e, sobretudo, dos pacientes. Neste caso o enxerto pediculado foi a opção por ser mais previsível do que o gengival livre num dente vestibularizado, revelando ser uma opção terapêutica viável para o tratamento de um caso de RT2.

http://doi.org/10.24873/j.rpemd.2019.12.543

\#082 Attachments de bola desgastados: resolução sem substituição - sobre um caso clínico

André Moreira*, Ricardo Batista, João Marques, Susana Oliveira, José Mário Rocha, Maria Helena Figueiral

Faculdade de Medicina Dentária Universidade do Porto

Introdução: A utilização de attachments metálicos cimentados em raízes naturais é uma excelente solução para aumentar a retenção, suporte e estabilidade de próteses dentárias, proporcionando uma satisfação superior relativamente às próteses convencionais. Embora a parte retentiva em teflon seja a mais atingida pelo desgaste, a fricção contínua entre metal e teflon provoca desgaste no componente metálico ao longo do tempo, o que diminui a retentividade das próteses. Estando a parte metálica cimentada a uma raiz, a sua remoção pode conduzir à fratura do dente pilar, comprometendo a viabilidade do tratamento. Encontrar uma solução alternativa e eficaz torna-se, pois, fundamental. Descrição do caso clínico: Paciente do sexo feminino, portadora de sobredentadura mandibular apoiada sobre as raízes dos caninos, cuja queixa principal era a falta de retenção e estabilidade da prótese. O exame clínico revelou a existência de um sistema tipo espigão fundido cimentado nas raízes dos dentes 33 e 43, com dois attachments de bola que apresentavam desgaste evidente. A abordagem do caso procurou evitar a descimentação dos attachments, recuperando a sua função. Neste sentido, utilizou-se o sistema Concave reconstrutivo esférico da Rhein 83, USA, disponível no mercado. O fabricante recomenda a preparação dos attachments de bola desgastados com brocas cilíndricas diamantadas e discos de polimento, a fim de os calibrar para posterior assentamento das novas esferas. Estas foram depois cimentadas com cimento de ionómero de vidro modificado autopolimerizável, FujiCEM2, GC. Por fim, as cápsulas de teflon foram substituídas e recapturadas em boca, verificando-se a oclusão. Discussão e conclusões: A sobredentadura sobre dentes é um tratamento protético simples e económico que, evitando o completo edentulismo, diminui a reabsorção óssea em torno dos dentes pilares, mantém os recetores periodontais e melhora a proporção coroa/raiz devido à secção coronária. Não isenta de limitações, a sobredentadura é um tratamento com boa aceitação por pacientes e médicos dentistas. A sua colocação pressupõe uma higienização cuidada dos dentes pilares e um controlo periódico das bases com eventual rebasamento e manutenção da dimensão vertical de oclusão. Este processo permitiu melhorar a retenção da sobredentadura ainda que os attachments de bola estivessem desadaptados e deformados, evitando a sua descimentação. Um ano após esta intervenção a sobredentadura mantém-se estável e retentiva.

http://doi.org/10.24873/j.rpemd.2019.12.544

\section{\#083 Guia de redução dentária - desenho CAD e impressão 3D - a propósito de um caso clínico}

Francisca Cavadas*, Diana Rodrigues, Tiago Marques, Cristina Paiva Figueiredo, Ana Margarida Silva, André Correia

Universidade Católica Portuguesa - Viseu

Introdução: Na elaboração de um planeamento para reabilitação com prótese removível a preparação pré-protética é uma etapa importante. Nesta fase, urge fazer uma análise da oclusão e decidir se esta será mantida, ou não, na reabilitação protética. De forma a melhorar a oclusão observada, poderão ser realizados ajustes oclusais por subtração, através de desgastes seletivos ou adição (restaurações). A recente evolução das tecnologias digitais conduziram uma alteração significativa dos conceitos de diagnóstico e tratamento em Prostodontia, porquanto a informação obtida através dos scanners e dos programas de desenho virtual (CAD) deverá ser utilizada para correta execução do tratamento. Descrição do caso clínico: Paciente do sexo feminino, 59 anos, ASA II dirigiu-se à Clínica Dentária Universitária da Universidade Católica de Viseu, para reabilitação do maxilar inferior. A paciente apresenta uma Classe II de Kennedy, tendo sido planeada a execução de uma prótese parcial removível. Após análise clínica e radiográfica verificou-se a existência de plano oclusal com alterações relevantes, devido à extrusão acentuada dos dentes 16, 15 e 14 por falta de dentes antagonistas. Foi efetuado o 'scanner intra-oral' do $1 .^{\circ}$ e $4 .^{\circ} \mathrm{Q}$ quadrante com o scanner DentalWings ${ }^{\circledR}$ Straumann e planeadas as reduções oclusais necessárias em CAD (programa Freeform Plus), por forma a corrigir a curva de Spee. Foi então desenhada uma guia de redução dentária com o programa Freeform Plus ${ }^{\circledR}$, posteriormente impressa numa impressora 3D Anycubic Photon -S, para facilitar o procedimento laboratorial e clínico. Foram efetuados os procedimentos necessários para a realização de uma Prótese Parcial Removível Esquelética até à etapa laboratorial de montagem dos dentes inferiores. Nessa etapa, o técnico de prótese reduziu a face oclusal do 16, 15 e 14 utilizando a guia previamente fabricada, e montou os dentes in- 
feriores em conformidade. Na consulta de prova de dentes, foi inserida a guia de redução e efetuados os desgastes oclusais pré-definidos. Testou-se a oclusão, efetuou-se um novo registo de mordida e solicitou-se a acrilização da prótese. Discussão e conclusões: Neste caso clínico apresenta-se uma alternativa às chaves de redução dentária 'analógicas', que podem ser efetuadas em resina, após redução dentária efetuada nos procedimentos laboratoriais. A guia de redução digital facilitou o procedimento permitindo efetuar uma redução mais precisa, de acordo com a oclusão a estabelecer com a nova prótese inferior.

http://doi.org/10.24873/j.rpemd.2019.12.545

\section{\#084 Dificuldades no registo intermaxilar em} pacientes com classe II, div. 1: Caso clínico

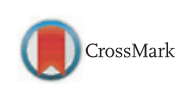

Ricardo Batista*, André Moreira, Pedro Fernandes, Paulo Almeida, José Mário Rocha, João Carlos Sampaio Fernandes

Faculdade de Medicina Dentária Universidade do Porto

Introdução: A reabilitação oral protética em pacientes classe II de Angle divisão 1 pode ser complexa, principalmente em pacientes com trespasse vertical e horizontal excessivo. Estes pacientes caracterizam-se por apresentar arcos funcionais congruentes em pequenas secções, uma dupla posição de mordida, primeiro contacto numa posição retrusiva do primeiro pré-molar maxilar e problemas fonéticos. Descrição do Caso clínico: A paciente recorreu à clínica de Reabilitação Oral da FMDUP. Apresentava além das características referidas, perda de dimensão vertical de oclusão (DVO) e plano oclusal alterado. Utilizava uma prótese parcial removível acrílica inferior desajustada e na arcada superior possuía uma reabilitação fixa implantossuportada em cantilever (implante 12 e 11 suspenso) com estética insatisfatória. Após anamnese, exame clínico e radiográfico, propôs-se uma reabilitação fixa dentossuportada ferulizada de 13 a 23 e uma prótese parcial removível esquelética inferior. Será descrita a situação problema, a técnica de registo intermaxilar por que optamos devido à perda da DVO e à necessidade de reestabelecer o esquema oclusal na posição de relação cêntrica (RC). O estudo em articulador mostrou que ao reabilitar numa posição próxima da posição da RC, perder-se-iam contactos anteriores. Determinou-se a posição do bordo do incisivo superior, a oclusão posterior e restabeleceu-se a DVO. No local dos rolos de articulação da esquelética, foram colocados blocos de acrílico liso que definiam a DVO e permitiam a desprogramação da mordida. Na face palatina dos dentes anteriores criaram-se contactos e guias anteriores. Após uma semana, a paciente referiu conforto e ausência de sintomas. Foi feito o registo intermaxilar com godiva de baixa fusão sobre os blocos de acrílico. Confirmada a oclusão na prova de dentes, terminou-se a prótese. Discussão e conclusões: A ausência de contactos posteriores promoveu uma posição protrusiva. Slavicek descreveu que na maioria dos adultos existe uma diferença de milésimos de milímetros entre intercuspidação máxima e RC. Contudo, em relações distais das bases ósseas poderá existir compensação articular. Apenas $41 \%$ da população apresenta uma classe I esquelética, para os restantes pacientes a abordagem do tratamento protético poderá variar seja no registo intermaxilar, disposição oclusal, número e inclinação dos dentes de forma a conferir função e estética simultaneamente.

http://doi.org/10.24873/j.rpemd.2019.12.546

\section{INVESTIGAÇÃO ORIGINAL}

\#085 Laser 830nm em defeitos ósseos críticos preenchidos com Bio-Oss e fibrina homóloga Tisseel

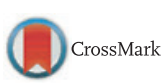

Daniela Vieira Buchaim*, Karina Torres Pomini, Rogério Leone Buchaim, Marcelie Priscila de Oliveira Rosso, Bruna Botteon Della Coletta, Jesus Carlos Andreo

Universidade de São Paulo - Faculdade de Odontologia de Bauru (FOB/USP), Universidade de Marília (UNIMAR); Centro Universitário de Adamantina (UNIFAI)

Objetivos: A terapia por fotobiomodulação a laser interfere diretamente na cicatrização tecidual, aumentando a circulação local, a proliferação celular e a síntese de colágeno. Entretanto, poucos estudos relatam a sua influência no processo de reparo ósseo de defeitos críticos preenchidos com selantes de fibrina, um scaffold amplamente utilizado em todo o mundo, com resultados promissores em estudos clínicos e experimentais. O objetivo deste estudo foi avaliar os efeitos da terapia por fotobiomodulação (TFBM) sobre o processo de reparo em defeitos críticos de calvária de ratos preenchidos com xenoenxerto Bio-Oss ${ }^{\circledR}(\mathrm{XE})$ e selante de fibrina homólogo Tisseel ${ }^{\circledR}$ (SFH). Materiais e métodos: 36 ratos foram submetidos à osteotomia circular de $8 \mathrm{~mm}$ no centro dos ossos parietais e separados aleatoriamente conforme os tratamentos: CS ( $\mathrm{n}=8)$ - defeitos preenchidos coágulo sanguíneo; XESFH ( $\mathrm{n}=10)$ - defeitos preenchidos com XE SFH; CSTFBM $(n=8)$ - defeitos preenchidos coágulo sanguíneo e bioestimulado (TFBM); XETFBM $(\mathrm{n}=10)$ - defeitos preenchidos com XE SFH e bioestimulado (TFBM). Após a inclusão das peças, os cortes foram corados com tricrômico de Masson, para a determinação do volume de novo osso, de tecido conjuntivo e partículas do biomaterial e picrosirius-red para avaliação das fibras colágenas. Os dados de densidade volumétrica foram submetidos aos testes de normalidade de Kruskal Wallis, seguidos teste post-hoc de Kruskal-Wallis para comparação grupos/período e teste t não pareado períodos/grupo $(\mathrm{p}<0,05)$. Resultados: Histologicamente CS e CSTFBM apresentaram deposição de osso imaturo na periferia e aos 42 dias após a cirurgia experimental o novo tecido ósseo tornou-se lamelar com fibras colágenas organizadas. XESFH e XETFBM exibiram infiltrado inflamatório junto às partículas, porém aos 42 dias apresentou-se em fase de resolução, principalmente XETFBM. Quantitativamente CSTFBM e XETFBM $(24.16 \pm 7.87 ; 6.84 \pm 5.32)$ apresentaram maiores médias do volume de densidade óssea em relação à CS e XESFH $(18.92 \pm 6.27 ; 3.96 \pm 1.86)$. Na análise de birrefringência XESFH e XETFBM, o percentual de birrefringência vermelha aumentou $(9.14 \%$ para $20.98 \%$ e $7.21 \%$ para $27.57 \%$ ), porém a birrefringência verde foi similar em relação ao período anterior, (3.3\% para $3.5 \%$ e $3.5 \%$ para $4.2 \%$ ). Conclusões: Conclui-se que TFBM influenciou positivamente 